\title{
Demand, control and support at work among sick-listed patients with neck or back pain. A prospective study
}

Kjersti Myhre, MD ${ }^{1}$, Bjørn Lau, Phd ${ }^{2,3}$ Gunn Hege Marchand, $\mathrm{MD}^{4}$, Gunnar Leivseth, $\mathrm{PhD}^{4}$, Erik Bautz-Holter, $\mathrm{PhD}^{1,5}$, Cecilie Røe, $\mathrm{PhD}^{1,5}$

1 Department of Physical Medicine and Rehabilitation, Oslo University Hospital, Ulleval, Oslo, Norway

2 National Institute of Occupational Health, Oslo, Norway

3 Lovisenberg Hospital, Oslo, Norway

4Faculty of Medicine, Department of Neuroscience, Norwegian University of Science and Technology, Trondheim, Norway

5 Faculty of Medicine, University of Oslo, Oslo, Norway

Correspondence to: Kjersti Myhre, Department of Physical Medicine and Rehabilitation, Oslo University Hospital, Ulleval, P.O.Box 4956 Nydalen, 0424 OSLO, Norway

Fax no: +4723027455

Telephone no: +4722119038

E-mail: kjersti.myhre@medisin.uio.no

\section{Acknowledgements}

The study was funded by the Norwegian Research Council. We thank Leiv Sandvik for statistical advice. 


\begin{abstract}
Purpose

The major aim of this study was to assess changes in perceived demand, control and support at work in neck and back pain patients over one year. We also hypothesised that perceived changes in demand, control and support at work were associated with clinical improvement, reduced fear-avoidance beliefs and successful return to work (RTW).
\end{abstract}

\title{
Methods
}

Four hundred and five sick-listed patients, referred to secondary care, with neck or back pain were originally included in an interventional study. Two hundred twenty-six patients who reported perceived psychosocial work factors at both baseline and one-year follow-up were later included in this prospective study.

\section{Results}

The quantitative demand score was the only work-related subscale that showed a change, with a one-year score significantly lower than the baseline score $(p=0.03)$. Additionally, the regression analyses showed that decreases in fear-avoidance beliefs about work were consistently related to decreases in demand and increases in control, whereas decreases in disability, anxiety and depression were related to increases in support subscales.

\section{Conclusions}

The perception of demand, control and support is fairly stable over one year in patients with neck and back pain, despite marked improvement in pain and disability. Disability, anxiety, depression and fear-avoidance beliefs about work were significantly associated with the perception of work environment, whereas neck and back pain were not associated.

\section{Keywords}

Sick Leave; Work; Musculoskeletal Diseases; Social support; Psychology 


\section{Introduction}

Neck and back pain are common ailments, and they are a major source of disability and work absences [1]. The disability from neck and low back pain is multi-factorial and not only related to medical factors $[2,3]$. In particular, the importance of working conditions has been emphasised [4]. Although the physical work environment is still important to ensure safety and health at the workplace, the psychosocial work environment is considered to be the most important factor in disability prevention [5]. Several models have been developed to explain the relationship between perceived psychosocial work environment and health problems [6]. One of the most applied models is the job-demand-control-support model (JDCS) developed by Karasek and colleagues [7]. JDCS is a three-dimensional model integrating job demand, decision latitude and social support at work. The model is based on research showing that workers with high-strain jobs and low social support have higher risk of cardiovascular disease [8]. The influences of demand, control and support at work in occupational neck and back pain have attracted considerable interest over the years. Recent reviews suggest that high demand, low control and low supervisor support are probably associated with the presence of neck and back pain $[9,10]$.

In a previous study, the model was applied to patients on sick leave referred to specialised care due to neck and back pain [11]. The patients perceived higher demands on their physical endurance than the reference population did. Additionally, the perceived demand, control and support were closely associated with fear-avoidance beliefs about work [11]. Although a recent study focused on a Norwegian worker population reported quantitative demand and 
decision control to be rather stable over a four-year period [12], we have no knowledge about the perception of demand, control and support over time in patient populations.

The view that a worker's health might influence the perceived psychosocial work environment has recently been proposed in a systematic review [13]. One of the most common mechanisms proposed to explain this "reversed effect" is the "perception" hypothesis. In this hypothesis, changes in worker well-being are suggested to cause an altered perception of the existing work environment, despite an actual unchanged work environment. Unhealthy workers might interpret their work environment more negatively over time due to reduced work capacity or by a selective recall of negative information or situations in individuals with poor affective health. Conversely, healthy workers are more likely to reinterpret their jobs positively over time [13]. In neck and back pain patients, a considerable reduction in pain and disability over the first year following a multidisciplinary intervention is expected [14, 15], as well as reduced emotional distress [14]. In addition, one of the priorities in multidisciplinary treatments is to reduce fear-avoidance beliefs, as high fear avoidance beliefs about work are found to be associated with prolonged sick leave and work loss [16]. Therefore, reduction in fear-avoidance beliefs about work is anticipated [14]. Furthermore, the majority of sick-listed back pain patients generally return to their usual work within one year [17-19].The extent to which the clinical recovery and return to work actually influence the perception of demand, control and support over time in a patient population is not known. The overall aim of this study was to assess changes in perceived demand, control and support at work in neck and back pain patients over one year. We also hypothesised that changes in demand, control or support at work were associated with clinical improvement, reduced fear avoidance beliefs and successful return to work (RTW). 


\section{Methods}

\section{Design}

This study was part of a randomised controlled multicentre trial of patients on sick leave due to neck and back pain [17]. All variables were measured at baseline and at one-year follow-up. The study was conducted in accordance with the Helsinki Declaration and was evaluated by the Regional Committees for Medical and Health Research Ethics in Southeast Norway (S09024b 2009/1000). It was authorised by the Data Protection for Research at Oslo University Hospital (1207-091208) according to the Norwegian guidelines.

\section{Participants}

Patients referred to the neck and back outpatient clinic at Oslo University Hospital (OUS), Ulleval and St. Olavs University Hospital (SOH), Trondheim, Norway, were recruited. All referred patients underwent a standardised medical examination to assess their eligibility for inclusion. To be included in the study, patients had to be between 18-60 years of age, employed and have sick leave duration between one and 12 months. The exclusion criteria were need for surgical treatment, cauda equina syndrome, symptomatic spinal deformities, osteoporosis with fractures, inflammatory rheumatic diseases, pregnancy, legal labour disputes, insufficient Norwegian language skills, cardiac, pulmonary, or metabolic disease with functional restrictions, and DSM-IV-diagnosed mental disorders.

Between August 2009 and August 2011, a total of 3,961 patients were screened for eligibility. The main reasons for ineligibility included not being sick-listed (50\%), unemployed (26\%), having a disorder suitable for surgical treatment (7\%) and a lack of Norwegian language skills (6\%). A total of 717 patients were eligible. Of these patients, 312 declined to participate. The remaining 405 patients were included in the intervention study (Figure 1) and were randomised to either work-focused multidisciplinary or clinical multidisciplinary intervention. 


\section{Assessments}

We recorded age, gender, native language, marital status, smoking status, highest level of education and occupation at baseline. Level of education was categorised into the four groups of primary school (7-10 years), vocational high school or general academic secondary school, college or university for less than 4 years and college or university $\geq 4$ years [20]. Occupation was categorised based on International Standard Classifications of Occupations, ISCO-88 [21]. Based on the ISCO-88 codes, we collapsed the occupations into four categories: low-skilled blue-collar workers (ISCO-codes 8 and 9), high-skilled blue-collar workers (ISCO-codes 6 and 7), low-skilled white-collar workers (ISCO-codes 4 and 5) and high-skilled white-collar workers (ISCO-codes 1, 2 and 3).

Intensity of pain during activity over the past week was reported on an 11-point numeric rating scale (NRS), ranging from 0 (no pain) to 10 (worst possible pain) [22]. Both neck/arm and back/leg pain were reported, and the highest pain rating of the two was used in the analyses. A minimum important change (MIC) of 2.0-2.5 points or 30\% improvement on NRS has previously been proposed [22, 23].

The Oswestry Disability Index (ODI) [24, 25] and Neck Disability Index (NDI) [26, 27] are composed of 10 items ranging from 0 to 5 . The summed score is presented as a percentage, where 0 represents no disability and 100 represents maximum disability. If more than five items were missing, no total ODI/NDI scores were calculated. A MIC of 30\% improvement or 10 points for ODI has been previously proposed [23]. For participants reporting disability due to both NP and LBP, the highest disability score was used in the analyses and referred to as the Disability Index (DI) score.

Level of anxiety and depression were measured by the Hospital Anxiety and Depression Scale (HADS) [28]. This has been found to perform well in screening for symptom severity and 
case evaluation of anxiety disorders and depression in somatic, psychiatric and primary care patients, as well as in the general population. The anxiety and depression subscales consist of seven items each, scored on a four-point scale from 0 to 3 . Each item is added together, resulting in a subscale score from 0 to 21 . One or two missing items in HADS were substituted by the subject's mean value. If more items were missing, no HADS score was computed.

Fear-avoidance was measured using Waddell's Fear-Avoidance Belief Questionnaire (FABQ), where each item was scored on a 7-point Likert scale ranging from 0 (strongly disagree) to 6 (strongly agree). The 7-item FABQ about work (FABQ-W) subscale was chosen in the analyses, as previous studies have shown an association between work-loss and disability [16]. The score ranges from 0 to 42 [16, 29], with high scores denoting strong fearavoidance beliefs. No missing values were allowed when calculating the FABQ scores.

The General Nordic Questionnaire for Psychological and Social Factors at Work (QPS Nordic)[30] is a questionnaire used to identify psychological and social factors at work. The validity and reliability have been documented previously [31]. The questionnaire was constructed on the basis of common questionnaires on this subject. The total questionnaire comprises questions that are found to be important for health and well-being, independent of specific models. The QPS Nordic items covering the dimensions of demand, control and social support were used in this study. An overview of the subscales and items studied in the present analyses is given in Table 1. QPS Nordic subscale scores were calculated as mean scores of completed items for those completing at least two thirds of the corresponding items. We replaced the total subscale by the average of the patient group if more than one third of the items in a subscale were missing (10 subjects at baseline and 13 subjects at one-year follow-up). In nine subjects, we replaced a complete missing subscale with the average value 
to achieve similar $\mathrm{N}$ for the nine QPS Nordic subscales. The average values were calculated and substituted in two subgroups, depending on whether the patient had returned to work or not.

In this prospective study of change in work environment, patients were defined as 'RTW' if they returned $100 \%$ or partly to their workplace.

\section{Data analysis and statistics}

We used paired $t$-tests to compare the average subscale values of the study population at baseline with one-year follow-up. To assess the size of the differences, Cohen's d values [32] were calculated. Cohen's d is defined as the difference between two means divided by the pooled standard deviation. We used the definition of effect sizes as given by Cohen, including small $(\mathrm{d}=0.2)$, medium $(\mathrm{d}=0.5)$ and large $(\mathrm{d}=0.8)$.

A hierarchical multiple regression analysis with each of the nine QPS Nordic subscale change-scores as dependent variables was performed. This was conducted to explore the relationship between the demographic characteristics, changes in clinical and mental health variables, work-focused intervention, RTW-status, and the subscales' change-score. First, we divided possible independent variables into two blocks: demographic and functioning blocks. Within each block, a series of standard univariate regression analyses were performed, and variables with $p$-values $<0.2$ were later included in the multiple regression analyses. In the demographic block the following variables were explored: age, gender, educational level, and occupations. Further, in the functioning block, we explored RTW-status, occurrence of workfocused intervention, and change-scores of pain intensity, DI, HADS-anxiety, HADSdepression, and FABQ-W. We controlled for age, gender, and the baseline value of the QPS Nordic subscale. All clinical variables were assessed with respect to normal distribution. Low co-linearity was found between the independent variables with tolerance greater than 0.9 . The 
final multiple regression analysis included variables with $\mathrm{p}$-value $<0.2$ from each block. The $\mathrm{R}^{2}$ value was reported for each step. A statistical significance level of $\mathrm{p}<0.05$ was adopted. Statistical analyses were performed using PASW Statistics, version 18 (IBM SPSS, IBM Corporation, NY, USA). 


\section{Results}

Response-rate

Although we had a total response rate of $74 \%$ at one-year follow-up, the QPS Nordic response rate amounted to $56 \%$, due to incomplete questionnaire responses. The characteristics of those patients who completed the QPS Nordic questionnaire are compared to those without a QPS Nordic response are shown in Table 2. Women were overrepresented as respondents $\left(\chi^{2}=7.5\right.$, $\mathrm{p}=0.006)$. In addition, respondents were older $(\mathrm{t}=2.0, \mathrm{p}=0.049)$ and reported higher levels of fear-avoidance beliefs about work $(\mathrm{t}=2.8, \mathrm{p}=0.005)$ than non-responders. However, the magnitude of these differences was small (Cohen's d 0.20-0.29).

\section{Patient characteristics}

Clinical characteristics of the patients at baseline and one year are reported in Table 3.

\section{Changes in demand, control and support subscales at one-year follow-up}

The mean Quantitative demands score at one-year follow-up was significantly lower than the mean baseline score $(\mathrm{p}=0.025)($ Table 4$)$. The magnitude of the difference was rather small $($ Cohen's $d=0.15$ ), and not present in the proportion of patients who were still $100 \%$ sicklisted at one year $(\mathrm{p}=0.64)$. No other significant differences were found among the measured subscales.

\section{Determinants for changes in demand, control, and support subscales}

The results from the univariate and multiple regression analyses for Quantitative demands are presented in Tables 5-7 and are used to illustrate the procedure in the regression analyses. Table 8 shows the final step in the hierarchical multiple regression analyses for all nine 
subscales. A positive value in any change-score variable denotes an increased one-year follow-up score compared with baseline score.

In the univariate analyses, age was associated with Quantitative demands, Control of decision and Control of work pacing, while gender was associated with Quantitative demands and Decision demands, educational level was associated with Quantitative demands, Decision demands and Support from co-workers, and occupation was associated with Quantitative demands, Decision demands, and Positive challenge at work, $(\mathrm{p}<0.2)$. Demographic variables remaining in the final model (Table 8$)$ were those associated with a subscale $(p<0.2)$ after the demographic box multiple regression analyses (only shown for Quantitative demands). However, age and gender were controlled for in all multiple analyses. The RTW-status was not associated with any subscale, and work-focused intervention was only significantly associated with increased Decision demands.

In the final multiple regression analyses, higher age was inversely associated with change in Quantitative demands and Learning demands. No other demographic variable showed associations in the final step. A decrease in FABQ-W was significantly associated with a decrease in all demands dimensions (Quantitative, Decision, Learning), and accounted for 3\% of the variability of the change. A decrease in DI (disability) was associated with an increase in Positive challenge at work, which accounted for $2 \%$ of the variability. A decrease in HADS-A (anxiety) and FABQ-W were significantly associated with rise in Control of work pacing, and explained $8 \%$ of the variability. No clinical variables were associated with Control of decision. In the support dimensions, a decrease in DI and HADS-A were associated with increased Support from superior and explained 5\% of the variability. Additionally, a decrease in HADS-D (depression) was associated with an increase in Support from friends and family. None of the investigated variables were significantly associated with Support from co-workers. 


\section{Discussion}

In this study, the population reported decreases in perceived Quantitative demands, whereas no other changes in perceived psychological and social work factors during one year were reported. Further, the regression analyses showed that reduction in fear avoidance beliefs were consistently related to reduction in demand and increase in control subscales, while reductions in disability, anxiety, and depression were related to increases in support subscales. Inclusion of these variables in the multivariate models explained only $2-8 \%$ of the variability of the subscales' changes.

The psychosocial constructs of demand, control, and support each include several aspects. Job control, as measured by QPS Nordic, refers to the individual's perceived possibility to choose between alternatives in the work situation and decide about work pace, breaks, flexitime, etc. In the same way, job demands refer to the time pressure and amount of work in a job, the demands for quick and complex decision making and attention, and requirement for better education or continuous training. To display the heterogeneous aspects of the job environment, we considered it necessary to examine each of the QPS Nordic subscales separately.

\section{Changes in demand, control and support at one-year follow-up}

Our first finding revealed that, except for Quantitative demands, eight subscales did not change at one-year follow-up. The QPS Nordic subscale Quantitative demands, which measures time pressure and amount of work, is probably a valid measure regardless of occupation or profession in this patient population. In contrast, Decision demands (demand for quick and complex decision making and attention) and Learning demands (demand for better education and continuous training), might vary among occupations or professions, but probably do not vary over a limited time period at the same workplace. Consequently, we did 
not expect the average score of the decision or learning demands to change in a patient population with different occupations.

In previous studies, subjective job control has been found to be highly correlated with objective job control data (based upon expert ratings or average group assessments) in workers $[33,34]$. As such, there is less reason to believe that job control will change significantly in the course of one year, even in a patient population. An exception might be with temporary work modifications.

Nonetheless, a previous study found that demand, control, and support subscale scores at baseline were quite similar to the scores of the reference worker population [11]. Furthermore, the rather stable quantitative demand and decision control over time in a Norwegian worker population [12] suggests that we could not expect major changes.

Although stability of quantitative demands and decision control in Norwegian workers over a four-year period [12], the reduced Quantitative demands in the present study might be explained by a concurrent substantial decrease in pain, disability and fear-avoidance belief. This may be supported by the "perception" hypothesis, suggesting that "changes in worker well-being may lead to an altered evaluation of existing job characteristics, even though the work environment itself may be unchanged"[13]. However, as this decline was only present in subjects with a successful return to work, it is possible that work modifications with lighter duties or reduced working hours had been introduced and facilitated the return to work. Nevertheless, we must assume that the demand, control, and support reported by patients who were still $100 \%$ sick-listed were based on their previous perception of the work environment. Unfortunately, we have no objective information indicating whether the work environment actually had been adapted.

Finally, the feasible changes in the work environment might not necessarily be associated with changes in 'major' work environment factors like demand, control, and support. In 
previous prospective studies among workers, other work factors such as role conflict, social climate, empowering leadership, and fair leadership were closely associated to the level of neck and back pain intensity $[35,36]$. Therefore, it is possible that the demand, control, and support concepts are not the only important work aspects to study among neck and back pain patients.

\section{Determinants for changes in demand, control and support subscales}

The second finding was the different associations between changes in the individual clinical factors and changes in demand, control, and support. A particularly interesting finding was a statistically significant association between reduced fear-avoidance beliefs about work and reduced perceptions of work demands. A reduced fear-avoidance belief about work was also associated with increased control of work pacing. More precisely, this means that if the subjective belief that work is harmful or might cause more pain decreases, this belief is associated with a concomitant decrease in subjective perceived job demands and an increase in control over work pace and breaks. Thus, opportunities for individual beneficial changes in these factors at the work place might seem important for an individual's perception of better coping and adjustment possibilities at work. However, a reduction in the fear-avoidance belief about work was not associated with changes in the perceived positive challenges at work, control of decisions, or social support. Control of decisions and the perception of the work as meaningful and positively challenging are probably more related to the occupation or the organisation's structure and do not change rapidly over time. Although changes in fearavoidance beliefs about work only explained a small part of the variability in demand and control change scores, it is consistent with previously found cross-sectional associations between work environment and fear-avoidance beliefs about work [11]. 
We would argue that the most important work environment assessment is provided by the subject, even though we cannot exclude that high level of pain and disability influence the perception of work demand, which subsequently is misclassified [34, 37]. In that case, we would expect pain and disability change scores to be associated with the changes in the work factors. Such influence was only observed for disability regarding positive challenges in work and support from superiors, whereas pain had no significant effect.

Although Airila et al. [38] did not find any association between the trajectory of musculoskeletal pain and job demand, they found close associations between high levels of job demand and poor interpersonal relations and depression. Also, in our study, improvements in anxiety and depression were more closely related to the work factors (i.e., control and support) than to improvement in neck or back pain.

The current study showed that a successful RTW status had no relation to the development of the perceived work environment. Similarly, no additional effect of a work-focused intervention compared to a general multidisciplinary intervention regarding change in work environment was found. Indeed, the unchanged demand, control, and support for the entire study population suggest that none of the interventions influence these factors. This finding suggests that development in demand, control, and support was partly associated with the individual's subjective clinical assessment but not with objective measureable factors such as RTW status or intervention type.

\section{Strength and limitations}

The strength of the present study is its prospective design and rather large sample size. By including two regional neck and back clinics and participants with a wide variety of occupations, workplaces, and employers, this study's aspects increase the external validity. A further strength is the combination of demographic, clinical, and work-related information 
about the participants. The application of scales from QPS Nordic, a validated comprehensive instrument designed for research into association between work and health as well as documentation of work conditions [31], was also a strength. However, the responsiveness of this instrument has, to the best of our knowledge, not been tested for a neck or back pain population.

Limitations to the present study are a low response rate of $56 \%$, although the analyses showed mainly similar demographic and clinical characteristics in the QPS Nordic responders versus QPS Nordic non-responders.

Additionally, the prospective design of the study contributes to new knowledge regarding perceived psychosocial work environment among sick-listed neck and back pain patients. However, because we include score changes both as dependent and independent variables in the regression analyses, we no longer have a traditional prospective regression analysis. This analysis limits us to associations between the change scores variables and not any causality based on the associations found.

\section{Conclusion}

In conclusion, the perception of demand, control and support at work was fairly stable over one year in patients with neck and back pain, despite marked improvement in pain and disability. Disability, anxiety, and depression were more closely associated with the perception of work environment than pain. Decreased fear-avoidance beliefs about work were consistently associated with decreased demands and increased control of work pacing.

\section{Conflict of interest}

The authors declare that they have no competing interest. 


\section{Figure legends}

Figure 1. Patient flow 
1. Hoy D, March L, Brooks P, Blyth F, Woolf A, Bain C, et al. The global burden of low back pain: estimates from the Global Burden of Disease 2010 study. Ann Rheum Dis 2014 Jun;73(6):968-74.

2. Pincus T, Burton AK, Vogel S, Field AP. A systematic review of psychological factors as predictors of chronicity/disability in prospective cohorts of low back pain. Spine (Phila Pa 1976 ) 2002 Mar 1;27(5):E109-E120.

3. Foss L, Gravseth HM, Kristensen P, Claussen B, Mehlum IS, Knardahl S, et al. The impact of workplace risk factors on long-term musculoskeletal sickness absence: a registry-based 5-year follow-up from the Oslo health study. J Occup Environ Med 2011 Dec;53(12):1478-82.

4. Pransky GS, Loisel P, Anema JR. Work disability prevention research: current and future prospects. J Occup Rehabil 2011 Sep;21(3):287-92.

5. WHO Healthy Workplace Framework and Model Synthesis Report. World Health Organization 2010.

http://www.who.int/occupational_health/activities/healthy_workplaces/en/index.html. Accessed 2014 Sep 22.

6. Pransky G, Gatchel R, Linton SJ, Loisel P. Improving return to work research. J Occup Rehabil 2005 Dec;15(4):453-7.

7. Karasek R, Theorell T. Healthy Work. New York:Basic Books; 1990.

8. Karasek R, Baker D, Marxer F, Ahlbom A, Theorell T. Job decision latitude, job demands, and cardiovascular disease: a prospective study of Swedish men. Am J Public Health 1981 Jul;71(7):694-705.

9. Macfarlane GJ, Pallewatte N, Paudyal P, Blyth FM, Coggon D, Crombez G, et al. Evaluation of work-related psychosocial factors and regional musculoskeletal pain: results from a EULAR Task Force. Ann Rheum Dis 2009 Jun;68(6):885-91.

10. Lang J, Ochsmann E, Kraus T, Lang JW. Psychosocial work stressors as antecedents of musculoskeletal problems: a systematic review and meta-analysis of stabilityadjusted longitudinal studies. Soc Sci Med 2012 Oct;75(7):1163-74.

11. Myhre K, Roe C, Marchand GH, Keller A, Bautz-Holter E, Leivseth G, et al. Fearavoidance beliefs associated with perceived psychological and social factors at work among patients with neck and back pain: a cross-sectional multicentre study. BMC Musculoskelet Disord 2013;14:329.

12. Christensen JO, Knardahl S. Time-course of occupational psychological and social factors as predictors of new-onset and persistent neck pain: a three-wave prospective study over 4 years. Pain 2014 Jul;155(7):1262-71. 
13. Tang K. A reciprocal interplay between psychosocial job stressors and worker wellbeing? A systematic review of the "reversed" effect. Scand J Work Environ Health 2014 Sep;40(5):441-56.

14. Brox JI, Sorensen R, Friis A, Nygaard O, Indahl A, Keller A, et al. Randomized clinical trial of lumbar instrumented fusion and cognitive intervention and exercises in patients with chronic low back pain and disc degenration. Spine (Phila Pa 1976 ) 2003 Sep 1;28(17):1913-21.

15. Keller A, Brox JI, Reikeras O. Predictors of change in trunk muscle strength for patients with chronic low back pain randomized to lumbar fusion or cognitive intervention and exercises. Pain Med 2008 Sep;9(6):680-7.

16. Waddell G, Newton M, Henderson I, Somerville D, Main CJ. A Fear-Avoidance Beliefs Questionnaire (FABQ) and the role of fear-avoidance beliefs in chronic low back pain and disability. Pain 1993 Feb;52(2):157-68.

17. Myhre K, Marchand GH, Leivseth G, Keller A, Bautz-Holter E, Sandvik L, et al. The effect of work-focused rehabilitation among patients with neck and back pain: a randomized controlled trial. Spine (Phila Pa 1976 ) 2014 Nov 15;39(24):1999-2006.

18. Indahl A, Velund L, Reikeraas O. Good prognosis for low back pain when left untampered. A randomized clinical trial. Spine (Phila Pa 1976 ) 1995 Feb $15 ; 20(4): 473-7$.

19. Storheim K, Brox JI, Holm I, Bo K. Predictors of return to work in patients sick listed for sub-acute low back pain: a 12-month follow-up study. J Rehabil Med 2005 Nov;37(6):365-71.

20. Statistisk sentralbyrå. Population's level of education. Statistics Norway 2014. http://www.ssb.no/utdanning/statistikker/utniv/aar. Accessed 2015 Jan 6. Norwegian.

21. Statistisk sentralbyrå. Standard for yrkesklassifisering. Statistics Norway 2011. http://www.ssb.no/a/yrke/. Accessed 2011 Jul 6. Norwegian

22. Farrar JT, Pritchett YL, Robinson M, Prakash A, Chappell A. The clinical importance of changes in the 0 to 10 numeric rating scale for worst, least, and average pain intensity: analyses of data from clinical trials of duloxetine in pain disorders. J Pain 2010 Feb;11(2):109-18.

23. Ostelo RW, Deyo RA, Stratford P, Waddell G, Croft P, Von KM, et al. Interpreting change scores for pain and functional status in low back pain: towards international consensus regarding minimal important change. Spine (Phila Pa 1976 ) 2008 Jan $1 ; 33(1): 90-4$.

24. Roland M, Fairbank J. The Roland-Morris Disability Questionnaire and the Oswestry Disability Questionnaire. Spine (Phila Pa 1976 ) 2000 Dec 15;25(24):3115-24.

25. Grotle M, Brox JI, Vollestad NK. Cross-cultural adaptation of the Norwegian versions of the Roland-Morris Disability Questionnaire and the Oswestry Disability Index. J Rehabil Med 2003 Sep;35(5):241-7. 
26. Vernon H, Mior S. The Neck Disability Index: a study of reliability and validity. J Manipulative Physiol Ther 1991 Sep;14(7):409-15.

27. Johansen JB, Andelic N, Bakke E, Holter EB, Mengshoel AM, Roe C. Measurement properties of the norwegian version of the neck disability index in chronic neck pain. Spine (Phila Pa 1976 ) 2013 May 1;38(10):851-6.

28. Bjelland I, Dahl AA, Haug TT, Neckelmann D. The validity of the Hospital Anxiety and Depression Scale. An updated. J Psychosom Res 2002 Feb;52(2):69-77.

29. Grotle M, Brox JI, Vollestad NK. Reliability, validity and responsiveness of the fearavoidance beliefs questionnaire: methodological aspects of the Norwegian version. J Rehabil Med 2006 Nov;38(6):346-53.

30. Lindstrøm K. User's guide for the QPSNordic: general Nordic questionnaire for psychological and socialfactors at work. 2000:603 ed. Copenhagen: Nordic Council of Ministers; 2000.

31. Dallner M, Elo AL, Gamberale F, Hottinen V, Knardahl S, Lindstrøm K, et al. Validation of the general Nordic Questionnaire (QPSNordic) for Psychological and Social Factors at Work. Copenhagen: Nordic Council of Ministers; 2000.

32. Cohen J. Statistical power analysis for the behvioral sciences. 2nd ed. Hillsdale, NJ:Lawrence Earlbaum Associates; 1988.

33. Theorell T, Hasselhorn HM. On cross-sectional questionnaire studies of relationships between psychosocial conditions at work and health--are they reliable? Int Arch Occup Environ Health 2005 Aug;78(7):517-22.

34. Solovieva S, Pensola T, Kausto J, Shiri R, Heliovaara M, Burdorf A, et al. Evaluation of the validity of job exposure matrix for psychosocial factors at work. PLoS One 2014;9(9):e108987.

35. Christensen JO, Knardahl S. Work and neck pain: a prospective study of psychological, social, and mechanical risk factors. Pain 2010 Oct;151(1):162-73.

36. Christensen JO, Knardahl S. Work and back pain: a prospective study of psychological, social and mechanical predictors of back pain severity. Eur J Pain 2012 Jul;16(6):921-33.

37. Blair A, Stewart P, Lubin JH, Forastiere F. Methodological issues regarding confounding and exposure misclassification in epidemiological studies of occupational exposures. Am J Ind Med 2007 Mar;50(3):199-207.

38. Airila A, Hakanen JJ, Luukkonen R, Lusa S, Punakallio A, Leino-Arjas P. Developmental trajectories of multisite musculoskeletal pain and depressive symptoms: The effects of job demands and resources and individual factors. Psychol Health 2014 Dec;29(12):1421-41. 
Figure 1. Patient flow

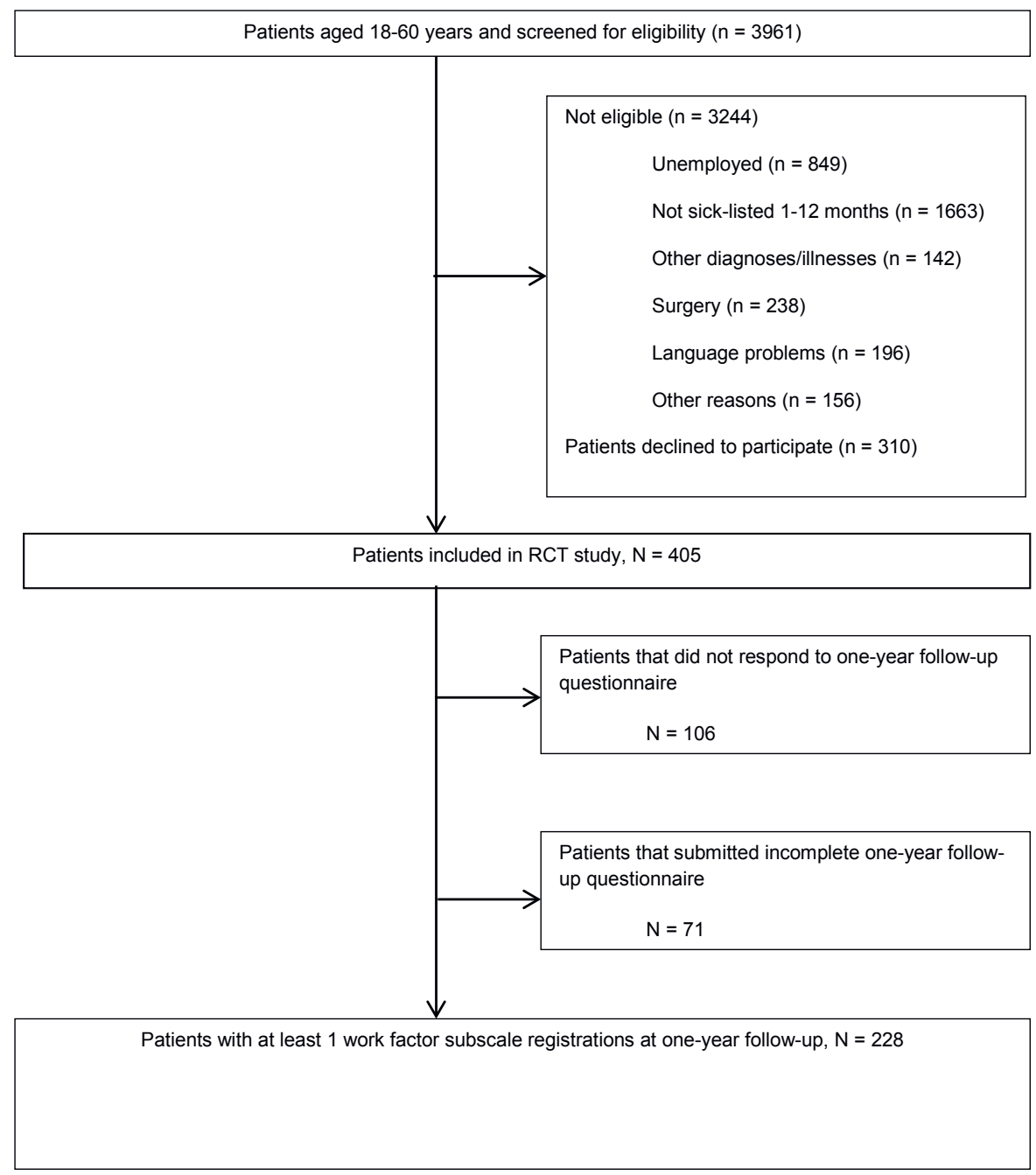


Table 1 Overview of subscales and items from QPS Nordic used in the analysis

\begin{tabular}{|c|c|c|c|}
\hline Composite subscale & Subscales & Number of items & Total range of scores \\
\hline \multirow[t]{3}{*}{ Demand } & Quantitative demands & 4 items & $1-5^{a}$ \\
\hline & Control demands & 3 items & $1-5^{a}$ \\
\hline & Learning demands & 3 items & $1-5^{a}$ \\
\hline \multirow[t]{3}{*}{ Control } & Positive challenge at work & 3 items & $1-5^{a}$ \\
\hline & Control of decision & 5 items & $1-5^{a}$ \\
\hline & Control of work pacing & 4 items & $1-5^{a}$ \\
\hline \multirow[t]{3}{*}{ Support } & Support from superior & 3 items & $1-5^{a}$ \\
\hline & Support from co-workers & 2 items & $1-5^{a}$ \\
\hline & Support from friends and family & 3 items & $1-5^{a}$ \\
\hline
\end{tabular}

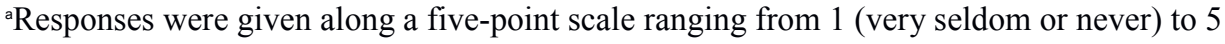
(very often or always). For each subscale, we reported the sum of the item score divided by the number of items (range 1-5). 


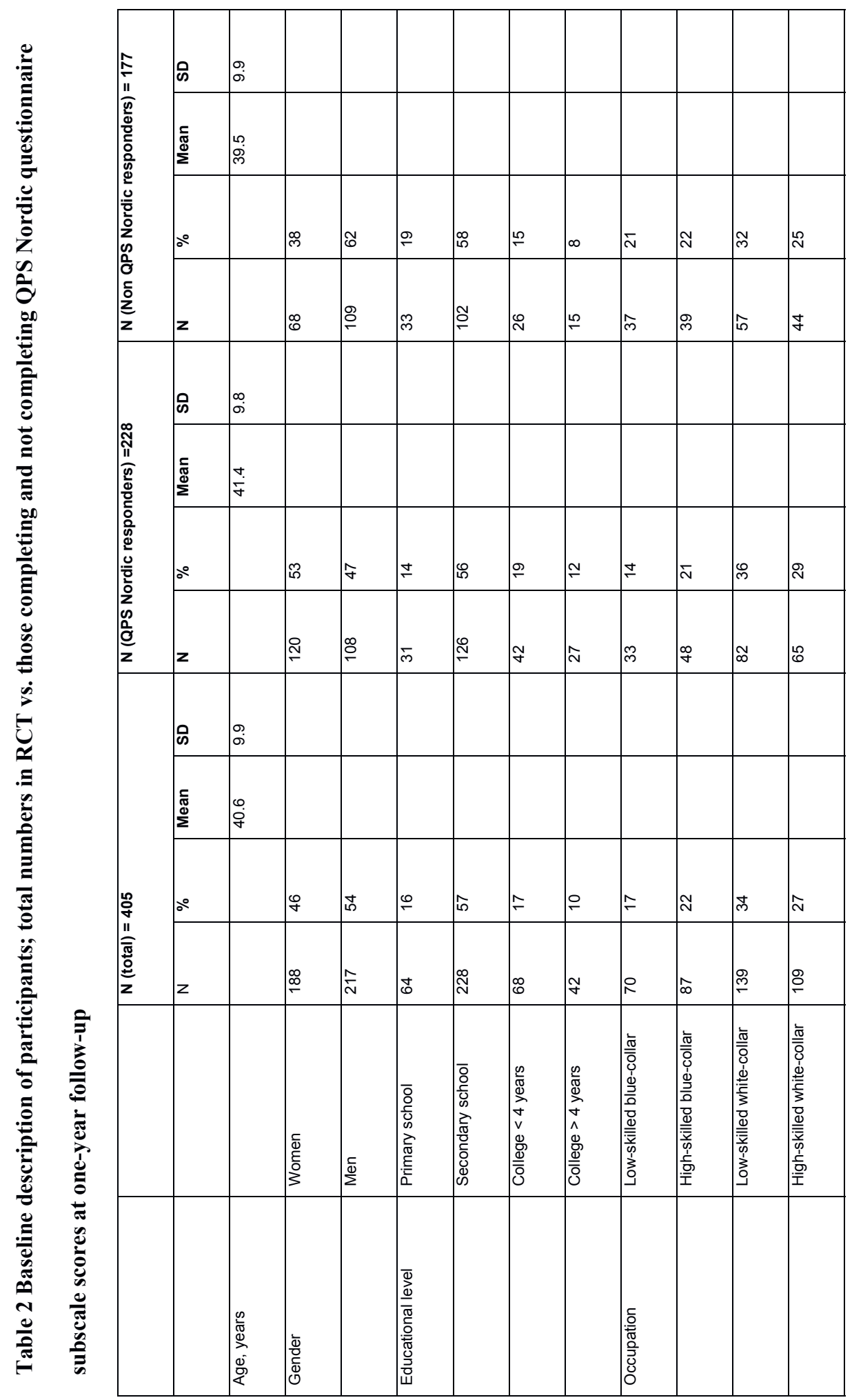




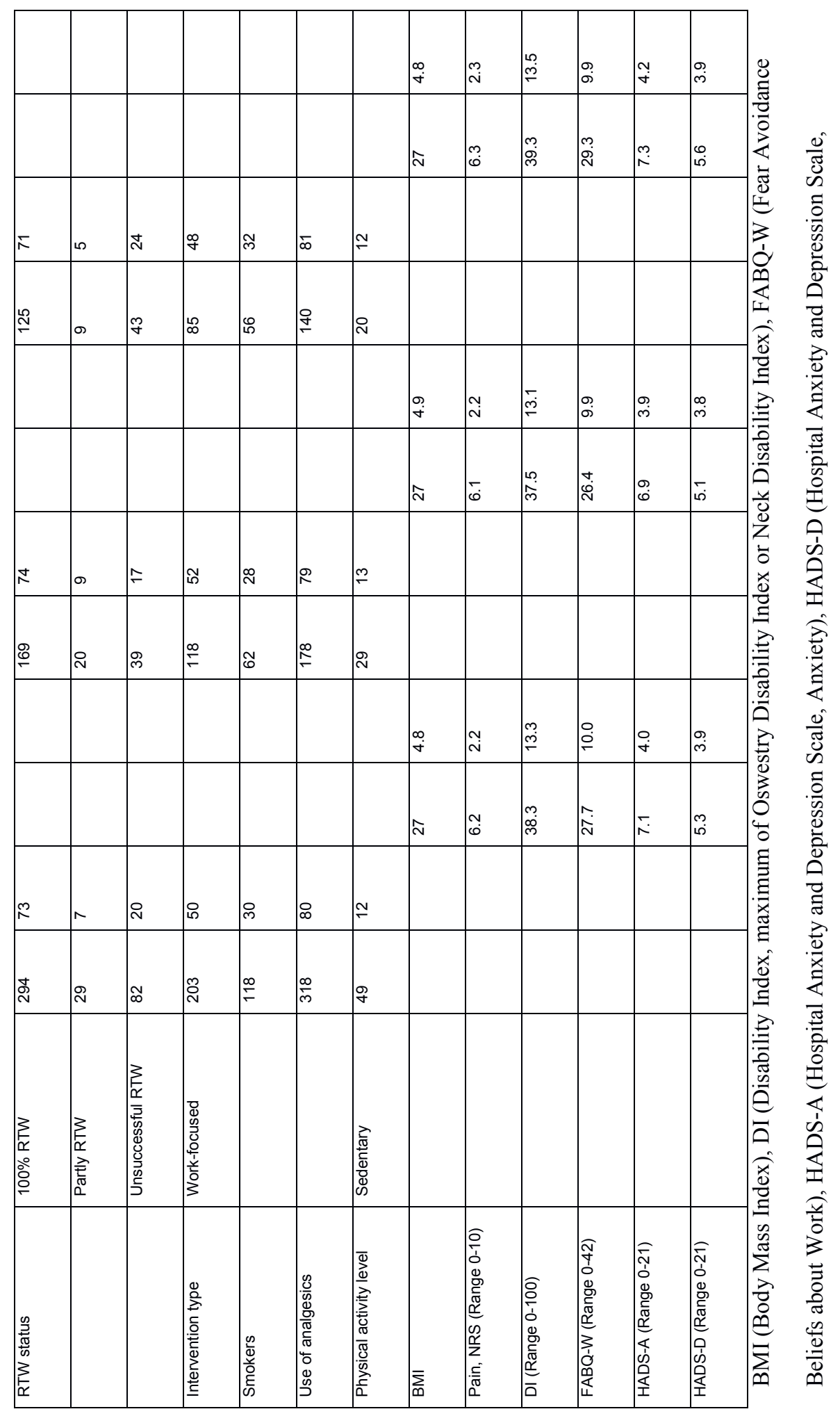




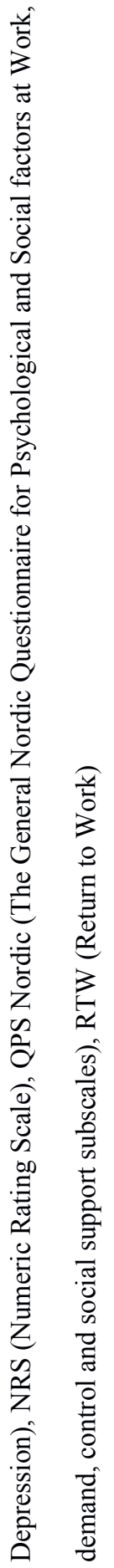


Table 3 Clinical characteristics of the study population at baseline and one-year followup and differences between the two points in time and t test p-value (values for QPS Nordic responders at both time points only)

\begin{tabular}{|c|c|c|c|c|c|c|c|c|}
\hline & \multicolumn{3}{|c|}{ Baseline } & \multicolumn{3}{|c|}{12 MND } & \multicolumn{2}{|c|}{ Baseline (t1) - one-year (t2) } \\
\hline & $\mathbf{N}$ & Mean & SD & $\mathbf{N}$ & Mean & SD & Mean (t1-t2) & t test $p$-value \\
\hline Pain (NRS) & 227 & 6.1 & 2.2 & 227 & 4.8 & 2.7 & 1.3 & $<0.001^{\mathrm{a}}$ \\
\hline ODI & 206 & 34.8 & 13.0 & 206 & 25.6 & 15.1 & 9.2 & $<0.001^{\mathrm{a}}$ \\
\hline NDI & 85 & 37.9 & 14.2 & 85 & 32.6 & 16.8 & 5.3 & $0.001^{\mathrm{a}}$ \\
\hline $\mathrm{DI}$ & 222 & 37.5 & 13.2 & 222 & 28.4 & 16.3 & 9.1 & $<0.001^{\mathrm{a}}$ \\
\hline FABQ-W & 206 & 26.5 & 9.8 & 206 & 20.7 & 12.7 & 5.8 & $<0.001^{\mathrm{a}}$ \\
\hline HADS-A & 225 & 6.9 & 3.9 & 225 & 6.1 & 4.2 & 0.8 & $0.001^{\mathrm{a}}$ \\
\hline HADS-D & 225 & 5.1 & 3.8 & 225 & 4.2 & 4.4 & 0.9 & $<0.001^{\mathrm{a}}$ \\
\hline
\end{tabular}

DI (Disability Index, maximum of Oswestry Disability Index or Neck Disability Index),

FABQ-W (Fear Avoidance Beliefs about Work), HADS-A (Hospital Anxiety and Depression Scale, Anxiety), HADS-D (Hospital Anxiety and Depression Scale, Depression), NDI (Neck Disability Index), NRS (Numeric Rating Scale), ODI (Oswestry Disability Index), QPS Nordic (The General Nordic Questionnaire for Psychological and Social factors at Work, demand, control and social support subscales)

a Significant at $0.05-$ level 
Table 4 Mean values of QPS Nordic subscales scorings at baseline, one-year, and differences between the two points in time and $t$ test $p$-value (values for QPS Nordic responders at both time-points only)

\begin{tabular}{|c|c|c|c|c|c|c|c|c|}
\hline & \multicolumn{3}{|c|}{ Baseline } & \multicolumn{3}{|c|}{12 MND } & \multicolumn{2}{|c|}{ Baseline (t1) - one-year (t2) } \\
\hline & $\mathbf{N}$ & Mean & SD & $\mathbf{N}$ & Mean & SD & Mean (t1-t2) & t test p-value \\
\hline Job demands & & & & & & & & \\
\hline Quantitative demands & 225 & 3.09 & 0.82 & 228 & 2.96 & 0.91 & 0.119 & $0.025^{\mathrm{a}}$ \\
\hline Decision demands & 225 & 3.47 & 0.78 & 226 & 3.56 & 0.90 & -0.085 & 0.062 \\
\hline Learning demands & 225 & 2.48 & 0.69 & 226 & 2.42 & 0.70 & 0.074 & 0.128 \\
\hline Job control & & & & & & & & \\
\hline Positive challenge at work & 225 & 3.94 & 0.83 & 225 & 3.98 & 0.87 & -0.058 & 0.236 \\
\hline Control of decision & 226 & 2.65 & 0.85 & 224 & 2.72 & 0.81 & -0.065 & 0.169 \\
\hline Control of work pacing & 226 & 2.67 & 1.20 & 224 & 2.69 & 1.14 & -0.022 & 0.724 \\
\hline Job support & & & & & & & & \\
\hline Support from superior & 225 & 3.54 & 1.08 & 219 & 3.61 & 1.06 & -0.076 & 0.246 \\
\hline Support from co-workers & 225 & 3.79 & 0.96 & 221 & 3.78 & 0.98 & -0.001 & 0.984 \\
\hline Support from friends & 225 & 4.00 & 0.97 & 222 & 3.92 & 1.01 & 0.069 & 0.227 \\
\hline
\end{tabular}

QPS Nordic (The General Nordic Questionnaire for Psychological and Social factors at Work, demand, control and social support subscales)

a Significant at 0.05 -level 
Table 5 Univariate and multivariate regression analyses with demographic factors as independent variables and Change of Quantitative Demands as the dependent variable at one-year follow up for sick-listed patients with neck and back pain

\begin{tabular}{|c|c|c|c|c|c|c|}
\hline & Univa & analyses & & Multi & alysis & \\
\hline Independent variables & $\beta$ & $\begin{array}{c}95 \% \mathrm{Cl} \\
\text { for } \beta\end{array}$ & $p$ value & B & $\begin{array}{c}95 \% \mathrm{Cl} \\
\text { for } \beta\end{array}$ & $p$ value \\
\hline Age & -0.107 & -0.02 to 0.002 & $0.11^{b}$ & -0.094 & -0.02 to 0.00 & 0.17 \\
\hline Gender (men vs. women) & 0.114 & -0.03 to 0.39 & $0.09^{b}$ & 0.080 & -0.11 to 0.36 & 0.29 \\
\hline Education level 2 (vs. level 1) & 0.037 & -0.15 to 0.27 & 0.59 & & & \\
\hline Education level 3(vs. level 1) & -0.123 & -0.52 to 0.02 & $0.07^{\mathrm{b}}$ & -0.121 & -0.52 to 0.03 & $0.08^{b}$ \\
\hline Education level 4 (vs. level 1) & 0.070 & -0.15 to 0.49 & 0.30 & & & \\
\hline $\begin{array}{l}\text { High-skilled blue-collar (vs. low-skilled blue- } \\
\text { collar) }\end{array}$ & 0.110 & -0.04 to 0.47 & $0.10^{\mathrm{b}}$ & 0.013 & -0.28 to 0.33 & 0.87 \\
\hline $\begin{array}{l}\text { Low-skilled white-collar (vs. low-skilled blue- } \\
\text { collar) }\end{array}$ & -0.103 & -0.39 to 0.05 & $0.12^{\mathrm{b}}$ & -0.072 & -0.36 to 0.12 & 0.33 \\
\hline $\begin{array}{l}\text { High-skilled white-collar (vs. low-skilled } \\
\text { blue-collar) }\end{array}$ & 0.006 & -0.22 to 0.24 & 0.93 & & & \\
\hline
\end{tabular}

${ }^{\mathrm{b}} \mathrm{p}$-value $<0.2$ 
Table 6 Univariate and multivariate regression analyses with RTW status, intervention type, Change in; pain, disability, HADS Anxiety, HADS Depression, and FABQ-W as predictors and Change of Quantitative Demand as the dependent variable at one-year follow up for sick-listed patients with neck and back pain, controlling for age and gender

\begin{tabular}{|c|c|c|c|c|c|c|}
\hline & Univa & analyses & & Multip & nalysis & \\
\hline Independent variables & $\beta$ & $\begin{array}{c}95 \% \mathrm{Cl} \text { for } \\
\beta\end{array}$ & $p$ value & $\beta$ & $\begin{array}{c}95 \% \mathrm{Cl} \text { for } \\
\beta\end{array}$ & $p$ value \\
\hline Age & & & & -0.179 & -0.025 to -0.004 & $0.006^{\mathrm{a}}$ \\
\hline Gender & & & & 0.123 & -0.07 to 0.44 & $0.058^{b}$ \\
\hline Quantitative demands baseline & -0.394 & -0.50 to -0.26 & $<0.001^{a}$ & -0.367 & -0.48 to -0.23 & $<0.001^{\mathrm{a}}$ \\
\hline $\begin{array}{l}\text { RTW status (at work vs. fully } \\
\text { sick-listed) }\end{array}$ & -0.029 & -0.34 to 0.21 & 0.66 & & & \\
\hline $\begin{array}{l}\text { Intervention type (work-focused } \\
\text { vs. control) }\end{array}$ & 0.077 & -0.09 to 0.33 & 0.25 & & & \\
\hline Change in pain & -0.048 & -0.05 to 0.02 & 0.48 & & & \\
\hline Change in DI & 0.077 & -0.00 to 0.01 & 0.26 & & & \\
\hline Change in HADS-A & 0.130 & 0.00 to 0.06 & $0.052^{b}$ & 0.073 & -0.014 to 0.047 & 0.28 \\
\hline Change in HADS-D & 0.031 & -0.02 to 0.04 & 0.64 & & & \\
\hline Change in FABQ-W & 0.189 & 0.004 to 0.03 & $0.007^{\mathrm{a}}$ & 0.161 & 0.002 to 0.023 & $0.17^{\mathrm{b}}$ \\
\hline
\end{tabular}

DI (Disability Index, maximum of Oswestry Disability Index or Neck Disability Index), FABQ-W (Fear Avoidance Beliefs about Work), HADS-A (Hospital Anxiety and Depression Scale, Anxiety), HADS-D (Hospital Anxiety and Depression Scale, Depression), RTW (Return to Work) 
${ }^{\text {a }}$ Significant with $\mathrm{p}$-value $<0.05$

${ }^{\mathrm{b}} \mathrm{p}$-value $<0.2$ 
Table 7 Stepwise multiple regression analyses with HADS Anxiety, and FABQ-W as predictors and Change in Quantitative Demands as the dependent variable at one-year follow up for sick-listed patients with neck and back pain, controlling for age, gender, baseline value and educational level 3

\begin{tabular}{|c|c|c|c|c|c|}
\hline Step & Independent variables & $\beta$ & $95 \% \mathrm{Cl}$ for $\beta$ & p value & $\mathbf{R}^{2}(\%)$ \\
\hline \multirow[t]{3}{*}{1} & Age & -0.109 & -0.02 to -0.00 & 0.12 & 3 \\
\hline & Gender & 0.084 & 0.09 to 0.36 & 0.23 & \\
\hline & Educational level 3 & -0.097 & -0.49 to 0.08 & 0.17 & \\
\hline \multirow[t]{4}{*}{2} & Age & -0.159 & -0.02 to -0.00 & $0.02^{a}$ & 16 \\
\hline & Gender & 0.109 & -0.03 to -0.38 & 0.10 & \\
\hline & Educational level 3 & -0.039 & -0.35 to 0.19 & 0.56 & \\
\hline & Quantitative demands baseline & -0.366 & -0.48 to -0.23 & $<0.001^{a}$ & \\
\hline \multirow[t]{5}{*}{3} & Age & -0.176 & -0.03 to -0.00 & $0.007^{a}$ & 19 \\
\hline & Gender & 0.127 & -0.01 to 0.41 & 0.051 & \\
\hline & Educational level 3 & -0.042 & -0.35 to 0.18 & 0.52 & \\
\hline & Quantitative demands baseline & -0.364 & -0.48 to -0.23 & $<0.001^{\mathrm{a}}$ & \\
\hline & Change in $F A B Q-W$ & 0.184 & 0.00 to 0.02 & $0.005^{\mathrm{a}}$ & \\
\hline
\end{tabular}

a Significant with $\mathrm{p}$-value $<0.05$ 
Table 8 The final step in the multiple regression analyses for each QPS subscale.

Possible predictors were RTW status, intervention type, Change in; pain, disability,

HADS Anxiety, HADS Depression, and FABQ-W and Change of current QPS scale was the dependent variable at one-year follow up for sick-listed patients with neck and back pain, controlling for age, gender and baseline value

\begin{tabular}{|c|c|c|c|c|c|}
\hline QPS subscale & Independent variables & $\beta$ & $95 \% \mathrm{Cl}$ for $\beta$ & $p$ value & $\mathbf{R}^{2}(\%)$ \\
\hline \multirow[t]{5}{*}{ Quantitative demands } & Age & -0.176 & -0.025 to -0.004 & $0.007^{a}$ & \multirow{5}{*}{19} \\
\hline & Gender & 0.127 & -0.01 to 0.41 & 0.051 & \\
\hline & Educational level 3 & -0.042 & -0.35 to 0.18 & 0.52 & \\
\hline & Quantitative demands baseline & -0.364 & -0.48 to -0.23 & $<0.001^{\mathrm{a}}$ & \\
\hline & Change in FABQ-W & 0.184 & 0.004 to 0.024 & $0.005^{\mathrm{a}}$ & \\
\hline \multirow[t]{5}{*}{ Decision demands } & Age & -0.090 & -0.15 to 0.00 & 0.18 & \multirow{5}{*}{12} \\
\hline & Gender & 0.104 & -0.04 to 0.32 & 0.13 & \\
\hline & Decision demands baseline & -0.271 & -0.34 to -0.12 & $<0.001^{\mathrm{a}}$ & \\
\hline & Intervention type & 0.095 & -0.05 to 0.30 & 0.16 & \\
\hline & Change in FABQ-W & 0.154 & 0.00 to 0.02 & $0.024^{a}$ & \\
\hline \multirow[t]{4}{*}{ Learning demands } & Age & -0.137 & -0.18 to -0.00 & $0.024^{a}$ & \multirow{4}{*}{30} \\
\hline & Gender & -0.041 & -0.17 to 0.16 & 0.97 & \\
\hline & Learning demands baseline & -0.517 & -0.64 to -0.40 & $<0.001^{\mathrm{a}}$ & \\
\hline & Change in $F A B Q-W$ & 0.162 & 0.00 to 0.02 & $0.007^{a}$ & \\
\hline \multirow[t]{4}{*}{ Positive challenge at work } & Age & 0.04 & -0.006 to 0.01 & 0.52 & \multirow{4}{*}{19} \\
\hline & Gender & -0.066 & -0.28 to 0.09 & 0.30 & \\
\hline & Positive challenge at work baseline & -0.41 & -0.47 to -0.25 & $<0.001^{\mathrm{a}}$ & \\
\hline & Change in $\mathrm{DI}$ & -0.165 & -0.01 to -0.002 & $0.008^{\mathrm{a}}$ & \\
\hline
\end{tabular}


Table 8 continued

\begin{tabular}{|c|c|c|c|c|c|}
\hline QPS subscale & Independent variables & $\beta$ & $95 \% \mathrm{Cl}$ for $\beta$ & p value & $\mathbf{R}^{2}(\%)$ \\
\hline \multirow[t]{5}{*}{ Control of decision } & Age & -0.034 & -0.011 to 0.006 & 0.58 & \multirow{5}{*}{27} \\
\hline & Gender & -0.031 & -0.22 to 0.13 & 0.61 & \\
\hline & Control of decision baseline & -0.455 & -0.49 to -0.28 & $<0.001^{\mathrm{a}}$ & \\
\hline & Change in $\mathrm{DI}$ & -0.124 & -0.01 to -0.000 & 0.068 & \\
\hline & Change in FABQ-W & -0.131 & -0.02 to 0.00 & 0.055 & \\
\hline \multirow[t]{5}{*}{ Control of work pacing } & Age & -0.070 & -0.02 to 0.006 & 0.30 & \multirow{5}{*}{13} \\
\hline & Gender & -0.026 & -0.29 to 0.20 & 0.69 & \\
\hline & Control of decision baseline & -0.160 & -0.32 to -0.03 & $0.019^{a}$ & \\
\hline & Change in HADS-A & -0.163 & -0.08 to -0.007 & $0.021^{a}$ & \\
\hline & Change in FABQ-W & -0.192 & -0.03 to -0.005 & $0.006^{\mathrm{a}}$ & \\
\hline \multirow[t]{5}{*}{ Support from superior } & Age & -0.015 & -0.013 to 0.010 & 0.80 & \multirow{5}{*}{29} \\
\hline & Gender & -0.066 & -0.35 to 0.09 & 0.26 & \\
\hline & Support from superior baseline & -0.495 & -0.56 to -0.35 & $<0.001^{\mathrm{a}}$ & \\
\hline & Change in $\mathrm{DI}$ & -0.146 & -0.017 to -0.002 & $0.019^{a}$ & \\
\hline & Change in HADS-A & -0.129 & -0.07 to -0.002 & $0.038^{\mathrm{a}}$ & \\
\hline \multirow[t]{6}{*}{ Support from co-workers } & Age & 0.041 & -0.008 to 0.016 & 0.49 & \multirow{6}{*}{27} \\
\hline & Gender & -0.049 & -0.32 to 0.13 & 0.42 & \\
\hline & Educational level 3 & 0.084 & -0.08 to 0.50 & 0.16 & \\
\hline & Support from co-workers baseline & -0.507 & -0.64 to -0.40 & $<0.001^{\mathrm{a}}$ & \\
\hline & Change in DI & -0.099 & -0.014 to -0.002 & 0.12 & \\
\hline & Change in HADS-A & -0.059 & -0.05 to 0.018 & 0.36 & \\
\hline \multirow[t]{4}{*}{ Support from friends/family } & Age & -0.083 & -0.018 to 0.003 & 0.18 & \multirow{4}{*}{23} \\
\hline & Gender & -0.094 & -0.37 to 0.04 & 0.12 & \\
\hline & Support from friends/family baseline & -0.459 & -0.51 to -0.30 & $<0.001^{\mathrm{a}}$ & \\
\hline & Change in HADS-D & -0.175 & -0.07 to -0.013 & $0.004^{\mathrm{a}}$ & \\
\hline
\end{tabular}


DI (Disability Index, maximum of Oswestry Disability Index or Neck Disability Index),

FABQ-W (Fear Avoidance Beliefs about Work), HADS-A (Hospital Anxiety and Depression Scale, Anxiety), HADS-D (Hospital Anxiety and Depression Scale, Depression)

${ }^{a}$ Significant with p-value $<0.05$ 